This is the author's final, peer-reviewed manuscript as accepted for publication. The publisher-formatted version may be available through the publisher's web site or your institution's library.

\title{
Standardization of a method to detect bovine sperm-bound anti-sperm antibodies by flow cytometry
}

M. C. Sardoy, D. E. Anderson, A. George, M. J. Wilkerson, S. Skinner, M. S. Ferrer

\section{How to cite this manuscript}

If you make reference to this version of the manuscript, use the following information:

Sardoy, M. C., Anderson, D. E., George, A., Wilkerson, M. J., Skinner, S., \& Ferrer, M. S. (2012). Standardization of a method to detect bovine sperm-bound anti-sperm antibodies by flow cytometry. Retrieved from http://krex.ksu.edu

\section{Published Version Information}

Citation: Sardoy, M. C., Anderson, D. E., George, A., Wilkerson, M. J., Skinner, S., \& Ferrer, M. S. (2012). Standardization of a method to detect bovine sperm-bound antisperm antibodies by flow cytometry. Theriogenology, 78(7), 1570-1577.

Copyright: () 2012 Elsevier Inc.

Digital Object Identifier (DOI): doi:10.1016/j.theriogenology.2012.06.026

Publisher's Link:

http://www.sciencedirect.com/science/article/pii/S0093691X12003962

This item was retrieved from the K-State Research Exchange (K-REx), the institutional repository of Kansas State University. K-REx is available at http://krex.ksu.edu 
$11 *$ Corresponding author: Department of Clinical Sciences, College of Veterinary Medicine,

12 Kansas State University, Manhattan, KS 66506, USA. Tel.: +1-785-532-5700. Fax: +1-785-532-

13 4989. Email address: $\underline{\text { mferrer@vet.k-state.edu }}$

$14{ }^{1}$ Present address at: Milton Equine Hospital, Campbellsville, Ontario, Canada

16 Abstract

17 
24 IgA-bound spermatozoa detected by flow cytometry. Including dead cells in the analysis

25 increased the percentage of IgG-bound spermatozoa in fixed (live and dead $18.6 \pm 9.7 \%$ and live

$261.3 \pm 0.5 \%)$ and non-fixed samples (live and dead $18.8 \pm 9.2 \%$, live $1.5 \pm 0.6 \%)(\mathrm{P}=0.0029)$,

27 as well as IgA-bound spermatozoa in fixed (live and dead $16.3 \pm 6.4 \%$, live $0.3 \pm 0.5 \%$ ) and

28 non-fixed samples (live and dead $21.4 \pm 4.6 \%$, live $1.0 \pm 0.5 \%)(\mathrm{P}=0.0041)$ (median $\pm \mathrm{SE}$ ) in

29 semen from ASA-negative bulls. Intra-sample, intra-assay and inter-assay coefficients of

30 variation $(\mathrm{CV})$ for determination of sperm-bound $\operatorname{IgG}$ were $0.8 \%, 4.6 \%$ and $5.3 \%$, respectively.

31 For determination of sperm-bound IgA, intra-sample, intra-assay and inter-assay CV were $2.8 \%$,

$328.4 \%$ and $40.3 \%$, respectively. In spite of the high inter-assay CV for IgA determination, all

33 ASA-positive bulls had high percentages of IgA-bound spermatozoa at all times. Flow cytometry

34 correctly identified ASA-positive bulls. Confocal laser microscopy confirmed the binding of

35 ASAs to the sperm head and cytoplasmic droplets, and less frequently to the mid and principal

36 piece. It was concluded that fixation was not necessary. Dead cells should be excluded from the

37 analysis since ejaculates with large numbers of dead cells can yield false-positive results. Flow

38 cytometry was accurate and reliable for detection of sperm-bound IgG and IgA and

39 discrimination between ASA-positive and ASA-negative bulls.

40

41 Keywords: Flow cytometry; anti-sperm antibodies; sperm-bound antibodies; immunoinfertility;

42 bovine

43

44 1. Introduction

45 
During spermatogenesis, developing germ cells express new surface antigens that are not

47 recognized as self. Sperm-specific surface antigens first appear on pachytene primary

spermatocytes [1]. The blood-testis barrier (BTB), removal of antigenic apoptotic cells by

49 phagocytosis and immunosuppressive factors released by Sertoli cells confer the testes an

50 immune privileged status. Disruption of the BTB induced by infectious, inflammatory or

51 degenerative conditions exposes sperm antigens to the immune system and results in formation

52 of anti-sperm antibodies (ASAs) [2]. In bulls, genital infection with Chlamydia sp., Brucella

53 abortus and Infectious Bovine Rhinotracheitis Virus was associated with concomitant presence

54 of ASAs [3,4]. Antisperm antibodies were also detected in bulls with seminal vesiculitis [5] and

55 orchitis [6]. The ASAs persisted in a bull with orchitis for $18 \mathrm{~m}$ after initial presentation [6].

56 Persistence of ASAs can account, at least in part, for the long-term effects of genital infection on

57 fertility. Exposure to electromagnetic pulses was also shown to alter the BTB and result in

58 formation of ASAs in mice [7]. Exposure to electromagnetic pulses from electric transmission

59 lines, generators and fences could represent an unidentified risk factor for immune-mediated

60 infertility in bulls.

61

Bovine ASAs can reduce penetration and fertilization of oocytes in vivo and in vitro,

62 sperm-zona pellucida secondary binding, the ability of capacitated spermatozoa to complete the

63 acrosome reaction and the motility of capacitated and non-capacitated spermatozoa [8-10].

64 Antisperm antibodies can impair fertility by contributing one more factor to an already

65 compromised semen sample, or by being the primary cause of idiopathic infertility. Their effect

66 on fertility depends on the location of the ASAs, their regional specificity, the antibody class,

67 isotype and load, and the antigen specificity [11-13]. Antibodies directed against sperm antigens

68 can be detected free in seminal plasma or serum. However, only those bound to the surface of 
spermatozoa are of significance for fertility [13]. Both IgA and $\operatorname{IgG}$, but not IgM, have a proven negative effect on fertility $[11,14]$. Therefore, an ideal diagnostic test should be able to identify sperm-bound ASAs and provide information about the proportion of ASA-bound spermatozoa in an ejaculate, the antibody class and load, and the regional specificity [15].

To date, most reports in veterinary medicine have involved the use of indirect techniques to detect ASAs in serum or seminal plasma. Sperm agglutination $[16,17]$ and immobilization tests [18] have been used to detect ASAs in bulls. However, these tests are insensitive and nonspecific [15]. Immunofluorescence [17], immunocytochemistry [3,19] and enzyme-linked immunosorbent assay $[8,20]$ have also been used in bulls. These techniques require fixation of the cell membranes. Fixation can result in non-specific binding of antibodies, exposure of intracellular antigens, denaturation of sperm antigens or membrane damage, resulting in falsepositive or false-negative results $[15,21]$. The mixed antiglobulin reaction and immunobeadbinding tests are most commonly used in human medicine [22]. These tests provide a semiquantitative estimation of the proportion of ASA-positive spermatozoa, and information on the antibody class and its location on the spermatozoa. However, both tests are based on counting motile spermatozoa bound to beads or latex particles. Therefore, the estimation is subjective. The tests require good sperm motility in the samples from the infertile patients if a direct test is used, or availability of a semen donor with good sperm motility if the indirect test is used [15]. Instead, flow cytometry allows objective and quantitative estimation of ASAs on the surface of living spermatozoa and is a sensitive, specific and repeatable test [15]. Flow cytometry also allows identification of the antibody class, isotype and load [15].

The use of flow cytometry to detect ASAs in bulls was only recently reported [6]. Moreover, a standardized direct technique to detect sperm-bound ASAs has not been developed 
92 in veterinary medicine. How the samples are processed and analyzed can have a significant

93 impact on the reliability of the results. When analyzing live cells, cross-linking of surface

94 antigens by multivalent antibodies, or of antigen-antibody (ag-ab) complexes by secondary

95 antibodies can cause aggregation of ag-ab complexes into patches and caps [21,23]. Patching

96 and capping is followed by shedding of the ag-ab complexes. Patching and capping can be

97 prevented by fixing the cell membranes prior to incubation with antibodies [21,23]. However,

98 as mentioned before, fixation can alter the membranes or antigens also giving misleading

99 results [15,21]. Another source of error is nonspecific uptake of antibody by dead spermatozoa.

100 Nonspecific binding can yield false-positive results if the proportion of dead cells in the

101 ejaculate is high [15].

102 The objectives of this study were to standardize some methodological and analytical

103 aspects of a direct technique to detect sperm-bound ASAs in bovine semen using flow

104 cytometry. The effect of fixation and inclusion of dead cells in the analysis were evaluated,

105 coefficients of variation for the standardized protocol were calculated and binding of ASAs to

106 bovine spermatozoa was confirmed with confocal laser scanning microscopy.

107

108 2. Materials and Methods

109

110 2.1. Animals

112 Four 1-year old Bos Taurus bulls of Angus breed were purchased from local producers. The

113 bulls were housed individually or in pairs in pens, and fed brome hay and water ad libitum, and 2

$114 \mathrm{lb}$ of sweet feed twice daily. Bulls were allowed to acclimate for one week prior to starting the 
115 experiments. To provide a known ASA-positive control, the bulls were immunized with 116 autologous spermatozoa as described below. When the percentage of ASA-bound spermatozoa

117 was $\geq 20 \%$, bulls were considered to have a positive response [24] and experiments were

118 initiated. Additionally, ten privately owned Angus bulls (standardization of the technique, $\mathrm{n}=5$;

119 calculation of coefficients of variation, $n=5$ ) classified as satisfactory breeders during routine 120 breeding soundness examination [25] were included as ASA-negative control bulls. Bulls were 121 considered satisfactory breeders if they had no gross abnormalities of their internal and external 122 genitalia, a scrotal circumference above the minimum recommended value for the age, $\geq 30 \%$ 123 individual sperm motility and $\geq 70 \%$ morphologically normal spermatozoa [25]. The study was 124 performed following Kansas State University's Institutional Animal Care and Use Committee's 125 guidelines. The bulls with experimentally-induced antibodies were euthanized at the end of the 126 study.

127

2.2. Semen collection and evaluation

Semen was collected using electroejaculation (SireMaster Original, ICE Corporation,

131 Manhattan, KS, USA). The accessory sex glands were massaged transrectally with a gloved hand 132 for 30 to $60 \mathrm{sec}$. A $6.5-\mathrm{cm}$ in diameter lubricated rectal probe was inserted into the rectum with 133 the electrodes facing ventrally. Electrical stimulation was applied with increasing intensity until 134 ejaculation [25]. A complete semen evaluation [25] was performed immediately after collection. 135 Semen was then used for immunization or for the experiments.

137 2.3. Immunization of bulls 
Immunizations were performed as described before with some modifications [18]. Ejaculated spermatozoa were washed three times by centrifugation at $900 \mathrm{x}$ g for $10 \mathrm{~min}$ diluted in warm

141 Dulbecco's phosphate buffered saline (DPBS, Invitrogen, Grand Island, NY, USA). Washed 142 spermatozoa, $1 \times 10^{9}$, were re-suspended to $1 \mathrm{~mL}$ in DPBS. One milliliter of Freund's complete 143 adjuvant (Sigma-Aldrich, St. Louis, MO, USA) was then added. Each bull was immunized with $1442 \mathrm{~mL}$ of inoculum containing $1 \times 10^{9}$ autologous spermatozoa. The inoculum was administered 145 intramuscularly in the neck in four different aliquots of $0.5 \mathrm{~mL}$ each. Booster immunizations 146 were administered to three bulls $22 \mathrm{~d}$ after the primary immunization. Semen was processed in the 147 same way as for primary immunizations but Freund's Incomplete Adjuvant (Sigma-Aldrich) was 148 used instead of Freund's Complete Adjuvant. One bull did not receive a booster immunization 149 since the response to the primary immunization was satisfactory.

2.4. Standardization of flow cytometry for detection of ASAs

The effect of fixing spermatozoa with formalin buffer solution prior to labeling on the ability 154 to detect sperm-bound ASAs was evaluated. One ejaculate was collected from each bull with 155 experimentally-induced ASAs $(n=4)$ and each ASA-negative bull $(n=5)$. Each ejaculate was 156 initially divided into two aliquots. Semen was diluted to $50 \times 10^{6}$ spermatozoa $/ \mathrm{mL}$ in DPBS 157 (non-fixed samples) or formalin buffer solution (FBS, Animal Reproduction Systems, Chino, 158 CA, USA) (fixed samples). Formalin buffer solution had been previously diluted 1:10 in DPBS. 159 After $10 \mathrm{~min}$ at room temperature, samples were washed three times by centrifugation and 160 labeled with fluorescein isothiocyanate (FITC)-labeled anti-bovine IgG or IgA, or their 
161 respective isotype control antibodies as described below. Samples were analyzed by flow

162 cytometry. The percentage of IgG- and IgA-bound spermatozoa was calculated including the

163 entire cell population (live and dead cells) or live cells only. Comparisons were made among

164 treatment groups: non-fixed samples including live cells only in the analysis, non-fixed samples

165 including both live and dead cells in the analysis, fixed samples including live cells only in the

166 analysis, and fixed samples including live and dead cells in the analysis.

167

168 2.5. Calculation of coefficients of variation

169

170

171 including dead cells in the analysis yielded false-positive results. Therefore, non-fixed samples

172 were used and only live cells were included in the analysis for calculation of coefficients of

173 variation $(\mathrm{CV})$. One ejaculate from each ASA-negative $(\mathrm{n}=5)$ and ASA-positive bull $(\mathrm{n}=4)$

174 was divided into five aliquots and processed in five replicates to calculate intra-assay CV. One of

175 the aliquots was evaluated five times to assess intra-sample CV. Only semen from ASA-positive

176 bulls was available for assessment of the inter-assay CV. Inter-assay CV was calculated

177 retrospectively from two ejaculates collected from each bull 6 to $20 \mathrm{~d}$ apart. The CVs were

178 calculated with the following formula: CV $(\%)=$ mean of standard deviations / mean x 100.

179

$180 \quad$ 2.6. Antibody labeling

181

182

Semen was diluted to a concentration of $50 \times 10^{6}$ spermatozoa $/ \mathrm{mL}$ in warm DPBS, and was

183

washed three times by centrifugation at $900 \mathrm{x} g$ for $10 \mathrm{~min}$ in DPBS. Then, $2.5 \mathrm{x} 10^{6}$ of washed 
184 spermatozoa were added to each of four tubes containing $320 \mu \mathrm{L}$ of DPBS. The corresponding

185

186

187

188

189

190

191

192

193

194

195

196

197

198

199

200

201

202

203

204

205

206

antibodies were added to each tube: $\operatorname{IgG}=30 \mu \mathrm{L}$ of FITC-labeled polyclonal goat anti-bovine $\operatorname{IgG~F(ab’)})_{2}(12.5 \mu \mathrm{g} / \mathrm{mL}$; Cat. No. 101-096-003, Jackson Immunoreseach Laboratories Inc., West Grove, PA, USA); IgG isotype control $=30 \mu \mathrm{L}$ of FITC-labeled polyclonal rabbit anti-goat $\operatorname{IgG~F}\left(\mathrm{ab}^{\prime}\right)_{2}(12.5 \mu \mathrm{g} / \mathrm{mL}$; Cat. No. 305-096-003; Jackson Immunoreseach Laboratories Inc.); $\operatorname{IgA}=20 \mu \mathrm{L}$ of FITC-labeled polyclonal rabbit anti-bovine $\operatorname{IgA}(12.5 \mu \mathrm{g} / \mathrm{mL}$; Cat. No. A10108F; Bethyl Laboratories, Montgomery,TX, USA); or IgA isotype control $=20 \mu \mathrm{L}$ of FITClabeled polyclonal goat anti-mouse IgA (12.5 $\mu \mathrm{g} / \mathrm{mL}$; Cat. No. A90-103F; Bethyl laboratories). A preliminary study was performed to evaluate saturating concentrations and select the appropriate concentration of each antibody (data not shown). The samples were incubated for 30 min at room temperature in the dark, followed by three washes by centrifugation at $900 \mathrm{x} g$ for 10 min in DPBS. Propidium iodide (PI, viability stain), $5 \mu \mathrm{L}$, was then added for simultaneous staining of dead cells.

\subsection{Flow Cytometry}

The percentage of IgG- and IgA-bound spermatozoa was assessed by flow cytometry (FACSCalibur, Becton Dickinson, San Jose CA, USA). From each sample, 10000 cells were analyzed at a rate of 1 to $2 \times 10^{3}$ cells /sec using DPBS as the sheath fluid. Data from these cells were collected using forward scatter as the size parameter. A gate containing spermatozoa was selected based on dot plot distribution of forward (size) versus side scatter (complexity parameter) to eliminate debris and epithelial cells from the analysis (Fig. 1). The FITC and PI signals were detected using a standard argon laser $(488 \mathrm{~nm})$ and emission filters $(535 \pm 30 \mathrm{~nm}$ 
207 for FITC and $585 \pm 30 \mathrm{~nm}$ for PI). The instrument was calibrated daily with standard beads so

208 that the CV of the forward scatter and fluorescence channels were $<5 \%$ on a daily basis.

209 Compensation for FITC emission into the PI detector or vice versa was done by establishing

210 quadrants on spermatozoa labeled only with PI or FITC-conjugated antibodies, followed by

211 electronic substraction of the FITC emission into the PI detector and PI emission into the FITC

212 detector. After color compensation, fluorescence emission data were collected with logarithmic

213 amplification for green fluorescence (FITC using FL1 detector) and orange-red fluorescence (PI

214 using FL2 detector). Quadrant settings were adjusted for each sample. The control quadrant

215 (lower left, LL) was marked on samples labeled with the isotype control to include $<1 \%$ of cells

216 as positive in the upper left (UL), upper right (UR) and lower right (LR) quadrants (Fig. 1). The

217 ASA-negative dead cells (PI stained) appeared in the UL quadrant, ASA-negative live cells (no

218 stain) in the LL quadrant, ASA-positive dead cells (dual stained) in the UR quadrant, ASA-

219 positive live cells (FITC stained) in the LR quadrant (Fig. 1). The percentage of ASA-positive

220 live spermatozoa (LR quadrant) was calculated considering only live cells (PI negative cells in

221 LL and LR quadrants) in the analysis. When including dead cells (PI positive cells), the

222 percentage of ASA-positive spermatozoa (LR and UR quadrants) was calculated considering all

223 quadrants.

224

225 2.8. Confocal laser scanning microscopy

226

227 Labeled spermatozoa from bulls with experimentally-induced antibodies were evaluated

228 under confocal laser scanning microscopy to confirm binding of the antibodies to the sperm

229 surface. No attempts were made to quantitatively evaluate the percentage of ASA-bound 
230 spermatozoa or the relative distribution of the binding sites. Spermatozoa were labeled with 231 FITC-labeled anti-bovine IgG or IgA as described above. After labeling, $10 \mu \mathrm{L}$ of FBS was 232 added to inhibit sperm motility and facilitate visual evaluation. A drop of sperm suspension was

233 evaluated on a microscope slide under a cover slide. The FITC signal was excited at $488 \mathrm{~nm}$ and 234 was collected with a band pass filter at a wavelength of 505-550 nm. Samples were assessed at 235 X20 and X40 and optical sections were collected (LSM 710 META, Carl Zeiss MicroImaging, 236 Thornwood, NY).

2.9. Statistical analysis

241 Distribution of the data was tested for normality using a Shapiro Wilk test. Data were not

242 normally distributed. To determine response to immunization, percentages of IgG- and IgA243 bound spermatozoa before and after the last immunization were compared using a Wilxocon 244 signed test. Only non-fixed live spermatozoa were included in this analysis. To assess the effect 245 of fixation and inclusion of dead cells in the analysis, differences in median percentages of IgG246 and IgA-bound spermatozoa among treatment groups were compared using a Friedman test. The

247 Friedman test is a non-parametric test that compares median values across treatments controlling 248 for bull. Since non-parametric tests were used, data were reported as median \pm SE. Differences 249 were considered significant at $\mathrm{P}<0.05$. 
Immunization with autologous spermatozoa induced a significant increase in the

254 percentage of both IgG-bound spermatozoa and IgA-bound spermatozoa. The percentage of IgG-

255 bound spermatozoa was $2.9 \pm 2.1 \%$ and $89.8 \pm 4.6 \%$ before and after immunization,

256 respectively $(\mathrm{P}=0.0209)$. The percentage of IgA-bound spermatozoa was $7.7 \pm 2.2 \%$ and $75.7 \pm$

$257 \quad 18.9 \%$ before and after immunization, respectively $(\mathrm{P}=0.0433)($ median $\pm \mathrm{SE})$.

258 There was no significant difference in the percentage of IgG- or IgA-bound spermatozoa

259 between samples fixed with FBS and non-fixed samples (Fig. 2). Including dead cells in the

260 analysis increased the percentage of $\operatorname{IgG}-(\mathrm{P}=0.0029)$ and $\operatorname{Ig} \mathrm{A}$-bound spermatozoa $(\mathrm{P}=0.0041)$

261 detected in semen samples from ASA-negative bulls (Fig. 2). However, median percentages of

262 ASA-bound spermatozoa did not differ among semen samples from ASA-positive bulls when

263 dead cells were included in the analysis (Fig. 2).

264

Intra-sample CV for determination of sperm-bound $\mathrm{IgG}$ was $0.8 \%$, intra-assay $\mathrm{CV}$ was

$2654.6 \%$ and inter-assay CV was $5.3 \%$. For determination of sperm-bound IgA, intra-sample CV

266 was $2.8 \%$, intra-assay CV was $8.4 \%$ and inter-assay CV was $40.3 \%$. Both antibody classes

267 bound to the acrosomal, equatorial and post-acrosomal areas of the sperm head, and to

268 cytoplasmic droplets (Fig.3). Least frequently, ASAs bound to the sperm midpiece and principal 269 piece.

270

271 4. Discussion

272

273 Systemic immunization with autologous spermatozoa induced an immune response in all

274 bulls characterized by an increase in sperm-bound IgG and IgA. Immunoglobulin G in genital

275 secretions is mostly derived from systemic circulation [26]. In the presence of an intact blood- 
276 testis or blood-epididymis barrier, IgG reaches the genital tract and binds to spermatozoa at the

277 rete testis or at ejaculation when spermatozoa contact the secretions of the accessory sex glands

278 [27-29]. On the other hand, IgA is produced locally [26]. Systemic immunization can result in

279 increased production of IgA within the genital tract, and increases in antigen-specific B cells in

280 the testis [29]. It is possible that systemic immunization of bulls with spermatozoa induced both

281 a systemic and mucosal immune response here. It is also possible that migration of activated

282 IgA-committed B cells from lymph nodes draining the injection site to the genital mucosa

283 contributed to the increase in sperm-bound IgA after immunization, as described in humans [30].

Recommendations for processing and evaluating bovine semen samples for detection of

sperm-bound ASAs by flow cytometry can be made based on the results of this study. Polyclonal

286 antibodies and $\mathrm{F}\left(\mathrm{ab}^{\prime}\right)_{2}$ fragments were used here. Since they are expected to react with all

287 subclasses, use of polyclonal antibodies may decrease the likelihood of obtaining false-negative

288 results [15]. Use of $\mathrm{F}(\mathrm{ab})_{2}$ fragments is also preferred to prevent non-immune binding of the Fc

289 portion of the IgG molecule to the sperm membrane [15], which occurs via disulfide

290 rearrangement at the cell surface in bulls [31]. Fixation of sperm membranes with formalin

291 buffer solution prior to labeling did not affect the ability to detect sperm-bound ASAs. Fixation

292 was performed to potentially prevent patching or capping of ag-ab complexes, which would have

293 yielded false-negative results. Mature spermatozoa have both mobile and non-mobile surface

294 antigens [32,33]. Patching and capping involve redistribution of mobile antigens in response to

295 multivalent ligands. Patching is a local clustering of molecules, while capping is the aggregation

296 of the clusters to a single area of the membrane. Following capping, molecules are shed from the

297 cell membrane [23]. While these phenomena were demonstrated in early spermatogenic cells [1],

298 patching and capping were not observed in late spermatids [1] or mature spermatozoa [34]. It 
was speculated that non-mobile antigens are inserted later in germ cell development, and that cross-linking between mobile and non-mobile antigens results in loss of capping in late spermatids [1] and spermatozoa. While fixation may be necessary to prevent lateral mobility of antigens, it can also alter the results by causing non-specific binding of antibodies, exposure of intracellular antigens, denaturation of sperm antigens and membrane damage $[15,21]$. It was concluded that since fixation of sperm membranes prior to labeling did not affect the results but increased processing times, this procedure could be avoided.

When dead cells were included in the analysis, false-positive results were obtained in samples from ASA-negative bulls. It is likely that non-specific binding of antibodies to dead cells or increased autofluorescence displayed by dead cells accounted for the increase in the percentage of fluorescently-labeled spermatozoa among ASA-negative bulls [15,35]. In ASApositive bulls, the percentage of ASA-bound spermatozoa was already high. Even when nonspecific binding to dead cells may have occurred, the difference may not have been large enough to be significant. It was concluded that dead cells should be excluded from the analysis to prevent false-positive results in ASA-negative bulls. This limits the use of flow cytometry to detect ASAs in bulls with necrozoospermia.

Coefficients of variation were all $<10 \%$, except for inter-assay CV for IgA-bound spermatozoa. It is not known if this high CV resulted from the low number of samples available, or from different frequencies of ejaculation that resulted in varying storage times and contact with ASA-loaded genital secretions. It is also possible that the variation reflected changes in antibody titers at different times post-immunization and was inherent to the model used rather than the test itself. The reason for the high inter-assay $\mathrm{CV}$ of the IgA test requires further investigation with more standardized sampling times. Nonetheless, the percentage of IgA-bound 
322 spermatozoa was $\geq 20 \%$ in all samples from all ASA-positive bulls. In spite of the high inter-

323 assay CV, the test was able to correctly identify IgA-positive bulls. With this exception, CVs in

324 this study were similar to those reported in the human literature [15]. It was concluded that flow

325 cytometry was accurate and reliable for detection of sperm-bound ASAs and discrimination

326 between ASA-positive and ASA-negative bulls.

327 Confocal laser microscopy confirmed binding of ASAs to the sperm surface. The

328 combination of flow cytometry and fluorescence microscopy provided an ideal diagnostic

329 approach. Flow cytometry allowed identification of sperm-bound ASAs and provided objective

330 and quantitative information about the antibody class and load. Additional use of fluorescence

331 microscopy provided information about the regional specificity of the ASAs. Due the lack of

332 reports on presence and behavior of naturally-occurring sperm-bound antibodies in bulls, it is

333 difficult to determine how detection of experimentally-induced antibodies compares with

334 detection of sperm-bound ASAs produced during bacterial infection or trauma. Studies are under

335 way to determine the reference ranges and prevalence of naturally-occurring sperm-bound ASAs

336 in satisfactory breeder beef bulls and bulls with reproductive pathology.

337 In conclusion, a direct technique to detect sperm-bound ASAs in bull semen was

338 developed. Flow cytometry was accurate and reliable for detection of sperm-bound ASAs and

339 discrimination between ASA-positive and ASA-negative bulls. When combined with

340 fluorescence microscopy, this method provided an ideal diagnostic approach for objective and

341 quantitative evaluation of sperm-bound ASAs in bulls.

Disclosure statement 
345 The authors declare that there is no conflict of interest that could be perceived as prejudicing the 346 impartiality of the research reported.

$348 \quad$ Funding

349

350 This work was supported by Kansas State University, College of Veterinary Medicine, Mentored 351 Clinical and Applied Translational Research, and NIH-P20-RR017686, COBRE Core B.

353 Acknowledgements

355 The authors thank Tammy Koopman for providing guidance and assay troubleshooting with flow 356 cytometry, and Joel Sannemann for his assistance on the use of the confocal laser microscope.

357 Thanks to Shelie Laflin, Meredyth Jones, Matt Miesner and Andrea Meyer for providing semen 358 samples from ASA-negative bulls. Robert Larson provided guidance with the statistical analysis.

360 References

362 [1] Romrell LJ, O’Rand MG. Capping and ultrastructural localization of sperm surface 363 isoantigens during spermatogenesis. Dev Biol 1978;63:76-3.

364 [2] Comhaire FH, Mahmound AMA, Depuydt CE, Zalata AA, Christophe AB. Mechanisms and 365 effects of male genital tract infection on sperm quality and fertilizing potential: the andrologist's 366 point of view. Human Reprod Update 1999;5:939-98. 
367 [3] Zralý Z, Benová J, Šišák M, Diblíková I, Švecová D, Zajícová A, Vêžník Z. Occurrence of 368 antibodies to sperms in blood sera of bulls and boars. Vet Med - Czech 1998;43:197-204.

369 [4] Hegazi AG, Ezzo O. Serum auto antibodies in buffaloes and cattle naturally infected with $370 \quad$ IBRV and brucella. Buffalo J 1995;3:325-30.

371 [5] Perez T, Carrasco LW. Autoimmunizacion espermatica en sementales bovinos como causa de 372 subfertilidad. IVth Int Congr Anim Reprod Artif Insem 1964; 5:527.

373 [6] Vlok I, Ferrer M, Sardoy M, Anderson D. Serum anti-sperm antibodies associated with 374 orchitis in a bull. Clinical Theriogenology 2009;1:251.

375 [7] Wang XW, Ding GR, Shi CH, Zeng LH, Liu JY, Li J, Zhao T, Chen YB, Guo GZ.

376 Mechanisms involved in the blood-testis barrier increased permeability induced by EMP.

377 Toxicology 2010;276:58-63.

378 [8] Kim CA, Parrish JJ, Momont HW, Lunn DP. Effects of experimentally generated bull 379 antisperm antibodies on in vitro fertilization. Biol Reprod 1999; Jun;60(6):1285-91.

380 [9] Coonrod SA, Westhusin ME, Naz RK. Monoclonal antibody to human fertilization antigen-1 381 (FA-1) inhibits bovine fertilization in vitro: application in immunocontraception. Biol Reprod 382 1994;51:14-23.

383 [10] Coonrod SA, Herr JC, Westhusin ME. Inhibition of bovine fertilization in vitro by 384 antibodies to SP-10. J Reprod Fertil 1996;107:287-97.

385 [11] Yeh WR, Acosta AA, Seltman HJ, Doncel G. Impact of immunoglobulin isotype and sperm 386 surface location of antisperm antibodies on fertilization in vitro in the human. Fertil Steril $387 \quad 1995 ; 63: 1287-92$. 
[12] Krause WKH. Sperm functions influenced by immune reactions. In: Immune Infertility, 389 Krause WKH and Naz RK, Eds., Springer Verlag Berlin Heidelberg, Berlin, Germany. 2009, p. $390 \quad 49-65$.

391 [13] Eggert-Kruse W, Christmann M, Gerhard I, Pohi S. Klinga K, Runnenbaum B. Circulating 392 antisperm antibodies and fertility prognosis: a prospective study. Hum Reprod 1989;4:513-20. 393 [14] Chamley LW, Clarke GN. Antisperm antibodies and conception. Semin Immunopathol $3942007 ; 29: 169-84$.

395 [15] Räsänen ML, Hovatta OL, Penttilä IM, Agrawal YP. Detection and quantitation of sperm396 bound antibodies by flow cytometry of human semen. J Androl. 1992;13:55-64.

397 [16] Wright PJ. Serum spermagglutinins and semen quality in the bull. Australian Vet J $398 \quad 1980 ; 56: 10-13$.

399 [17] Purswell BJ, Dawe DL, Caudle AB, Williams DJ, Brown J. Spermagglutinins in serum and 400 seminal plasma of bulls and their relationship to fertility classification. Theriogenology $401 \quad 1983 ; 20: 375-81$.

402 [18] Menge AC, Christian JJ Jr. Effects of auto- and iso-immunization of bulls with semen and 403 testis. Int J Fertil 1971; 16:130-8.

404 [19] Fayemi O. Sperm antibodies and reproductive efficiency in the zebu cattle in south-western 405 Nigeria. Pakistan Vet J 2005; 25:111-4.

406 [20] Zralý Z, Benová J, Diblíková I, Švecová D, Kummer V, Mašková J, Vêžník Z. Antisperm 407 antibodies in blood sera of bulls and correlations with age, breed and ejaculate quality. Acta Vet 408 Brno 2002;71:303-8. 
[21] Nikolaeva MA, Kulakov VI, Korotkova IV, Gulobeva EL, Kuyavskaya DV, Sukhikh GT. Antisperm antibodies detection by flow cytometry is affected by aggregation of antigen-antibody complexes on the surface of spermatozoa. Human Reprod 2000;15:2545-53.

[22] Krapez JA, Hayden CJ, Rutherford AJ, Balen H. Survey of the diagnosis and management of antisperm antibodies. Hum Reprod 1998;13:3363-7.

[23] Santoso S, Zimmerman U, Neppert J, Mueller-Eckhardt C. Receptor patching and capping of platelet membranes induced by monoclonal antibodies. Blood 1986;67:343-9.

[24] Nicholson SC, Robinson JN, Sargent IL, Barlow DH. Detection of antisperm antibodies in seminal plasma by flow cytometry: comparison with the indirect immunobead binding test. Fertil Steril 1997;68:1114-9.

[25] Chenoweth PJ, Hopkins FM, Spitzer JC, Larsen RE. Guidelines for using the bull breeding soundness evaluation form. Clin Theriogenology 2010;2:43-9.

[26] Mestecky J, Fultz PN. Mucosal immune system of the human genital tract. J Infect Dis 1999;179(suppl 3):S470-4.

[27] Knee RA, Hickey DK, Beagley KW, Jones RC. Transport of IgG across the blood-luminal barrier of the male reproductive tract of the rat and the effect of estradiol administration on reabsorption of fluid and IgG by the epididymal ducts. Biol Reprod 2005;73:688-94. [28] Wang Y, Ben K, Cao X, Wang Y. Transport of anti-sperm monoclonal IgA and IgG into murine male and female genital tracts from blood. Effect of Sex Hormones. J Immunol 1996;156:1014-9.

[29] Cunningham KA, Carey AJ, Finnie JM, Bao S, Coon C, Jones R, Wijburg O, Strugnell RA, Timms P, Beagley KW. Poly-immunoglobulin receptor-mediated transport of IgA into the male 
431 genital tract is important for clearance of Chlamydia muridarum infection. Am J Reprod

432 Immunol 2008; 60:405-14.

433 [30] Brokstad KA, Cox RJ, Olofsson J, Jonsson R, Haaheim LR. Parenteral influenza

434 vaccination induces a rapid systemic and local immune response. J Infect Dis 1995;171:198-203.

435 [31] Richards JM, Witkin SS. Non-immune IgG binding to the surface of spermatozoa by

436 disulphide arrangement. Clin Exp Immunol 1984;58:493-501.

437 [32] O'Rand MG, Metz CB. Immunofluorescence of rabbit spermatozoa treated with anti-sera to

438 a single sperm surface membrane glycoprotein and wheat germ agglutinin. J Cell Biol

$439 \quad 1975 ; 67: 317 a$.

440 [33] Gaunt SJ, Brown CR, Jones R. Identification of mobile and fixed antigens on the plasma

441 membrane of rat spermatozoa using monoclonal antibodies. Exp Cell Res 1983;144:275-284.

442 [34] Koehler JK. Studies on the distribution of antigenic sites on the surface of rabbit

443 spermatozoa. J Cell Biol 1975;67:647-59.

444 [35] Schmid I, Ferbas J, Uittenbogaart CH, Giorgi JV. Flow cytometric analysis of live cell

445 proliferation and phenotype in populations with low viability. Cytometry 1999;35:64-74.

446

447

448

449

450

451

452

453 

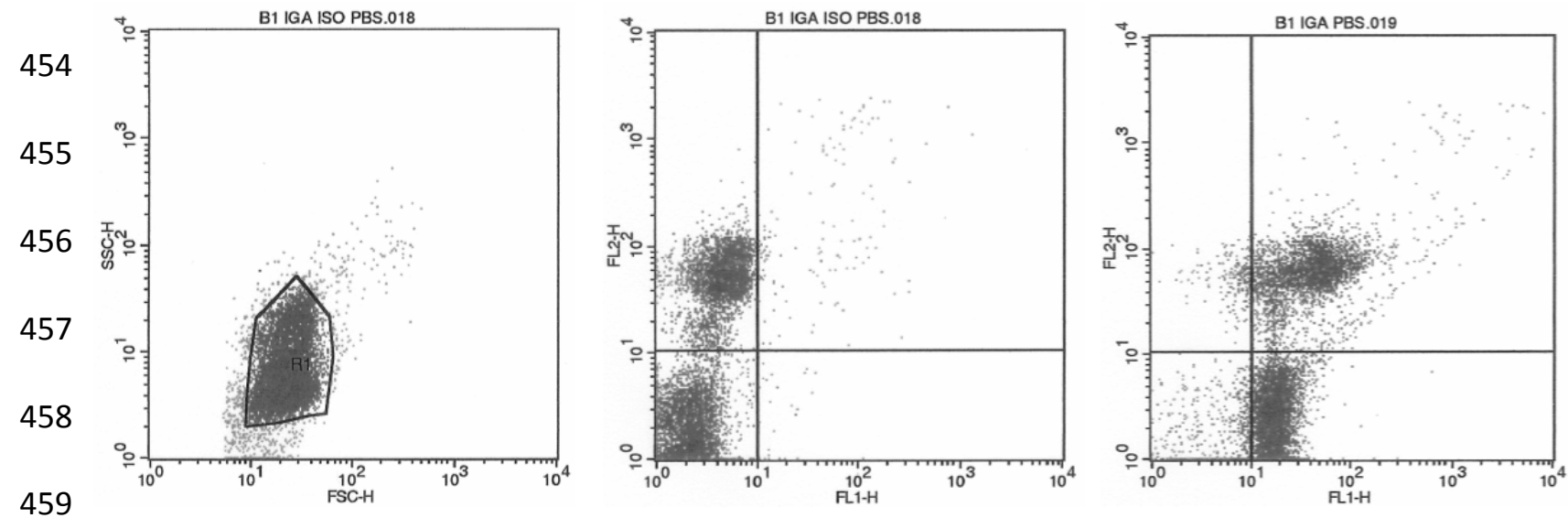

460 Fig. 1. Example of dot plot distribution of forward (FSC-H) and side scatter (SSC-H) of a

461 washed sperm sample (left panel). The cells within gate 1 (R1) represent the population of

462 spermatozoa. Example of dot plot distribution of two-color analysis of a sperm sample from a

463 bull with experimentally-induced anti-sperm antibodies stained with FITC-labeled anti-mouse

464 IgA (isotype control) (central panel) or FITC-labeled anti-bovine IgA (right panel). Fluorescence

465 data was collected with logarithmic amplification for green (FITC; FL1-H) and red (PI; FL2-H)

466 fluorescence. The anti-sperm antibody (ASA)-negative dead sperm appeared in the upper left

467 (UL) quadrant, ASA-negative live sperm in the lower left (LL) quadrant, ASA-positive dead

468 sperm in the upper right (UR) quadrant, and ASA-positive live sperm in the lower left (LR)

469 quadrant.

470

471

472

473

474

475

476 

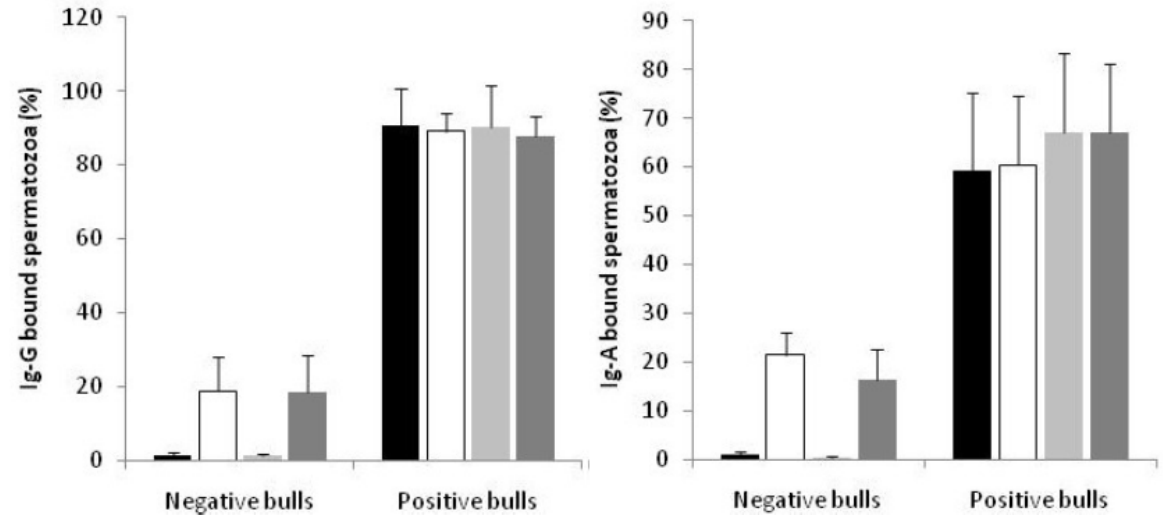

- Live non-fixed $\quad$ Live and dead non-fixed Live fixed $\quad$ Live and dead fixed

484 Fig. 2. Percentage of anti-sperm antibody (ASA)-bound spermatozoa in samples fixed with

485 formalin buffer solution and non-fixed samples, and including live only or live and dead cells in

486 the analysis. ${ }^{\text {a,b }}$ Values with different superscript differ significantly among treatments within

487 ASA-negative bulls (Median $\pm \mathrm{SE}$ ).

488

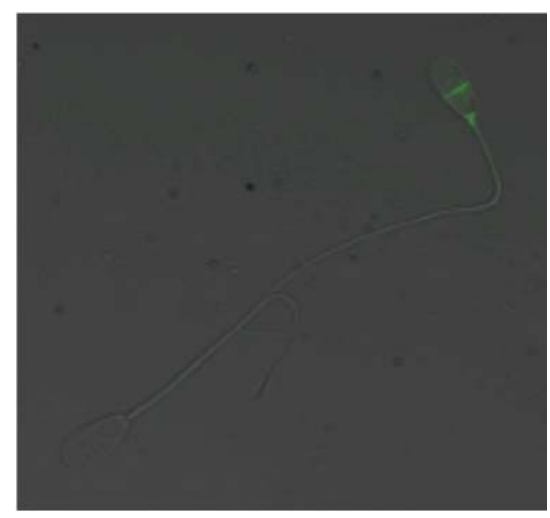

Fig. 3. Antibody-negative spermatozoa (left) and spermatozoa with IgG binding to the equatorial 496 area and the junction between the sperm head and midpiece (right). 